MOBILE MUSIC BUSINESS IN J APAN AND KOREA:

COPYRIGHT MANAGEMENT INSTITUTIONS AS A REVERSE SALIENT

Akira Takeishi and Kyoung-J oo Lee

IIR Working Paper WP\#04-02

February 2004

Institute of Innovation Research

Hitotsubashi University

Tokyo, Japan

http://www.iir.hit-u.ac.jp 


\title{
MOBILE MUSIC BUSINESS IN JAPAN AND KOREA: \\ Copyright Management InStitutions AS A ReVERSE SALIENT
}

Paper submitted to A ustin M obility Roundtable, 2004

First Draft: October 31, 2003

Revised: February 15, 2004

\author{
Akira Takeishi* and Kyoung-Joo Lee** \\ *Professor, Institute of Innovation Research \\ takeishi@iir.hit-u.ac.jp \\ **PhD Candidate, Graduate School of Commerce and Management \\ leekjoo@hotmail.com \\ Hitotsubashi University \\ 2-1 Naka, Kunitachi, Tokyo 186-8603, Japan \\ Phone: +81-42-580-8425, Fax: +81-42-580-8410 \\ URL: http:/ / www.iir.hit-u.ac.jp/
}

\begin{abstract}
A bstract
This paper examines the development process of music businesses on mobile Internet in Japan and Korea, two leading countries in the world that have been enjoying rapid growth of mobile Internet businesses. Based on the "Large Technological System" perspective (Hughes 1983, 1989), this paper sees music copyright management institutions as a "reverse salient" in the large technological system of mobile music businesses. We argue that the development of mobile music business has been and will be dependent on how to revise copyright management institutions in accordance with changes and advancement of technologies and other sub-components in the large technological system.
\end{abstract}

For discussion and comment only; please do not reproduce, cite, or quote without the authors' permission. 


\section{O bjectives}

This paper examines the devel opment process of music businesses on mobile Internet in Japan and Korea. Both Japan and Korea have been the forefront runners of mobile Internet usage in the world. Among a variety of applications, music related services have become one of the most important businesses in both countries' mobile commerce markets. The world's first mobile Internet has been launched in Japan, and the ringing melody download service has been an engine of mobile Internet market growth, becoming the largest mobile Internet business in the country. Similarly in Korea, mobile music services, including those to download ringing melodies and ring back songs, have been the most popular mobile content services. As their mobile communication systems enter into the 3rd Generation, music download service has also been introduced, with an expectation that it would lead to a full-blown mobile music business in the near future.

Mobile music businesses in Japan and Korea would therefore provide researchers with precious research materials to probe into causes and conditions for the development of mobile commerce. Especially, understanding common characteristics as well as national specific differences between the two leading countries could provide important analytical cues to project the future development of mobile Internet businesses in the world.

How have mobile music businesses been developed and evolved in Japan and Korea? What are critical factors behind the growth of the businesses? To reason out possible answers for these questions, this paper draws on "Large Technological Systems" perspective (Hughes 1983, 1989) as an analytical framework. The mobile music businesses have evolved in dynamic interactions of technologies, firms, and institutions, all of which constitute the large technological system of mobile Internet. In particular, this paper refers to the concept of "reverse salient" in the large technological system, and argues that institutions to manage music copyrights could be regarded as a reverse salient that plays a crucial role in the developmental process of mobile music business.

This paper is organized as follows. First, we introduce the concept of large technological systems (LTS) as an analytical perspective, with a focus on reverse salient in LTS. Second, we briefly describe mobile music businesses in the two countries, and overview their development process. Third, we attempt to explain the characteristics 
and development mechanism of the two countries' mobile music businesses based on the analytical concept of reverse salient in LTS, with a primary attention to music copyright control and management institutions. We conclude this paper by providing some implications for practitioners and researchers.

\section{Reverse Salient in a Large Technological System: An A nalytical Framework}

A large technological system is a collection of distinct but interrelated sub-systems, each of which is designed to perform independent tasks but all are sophisticatedly organized so as to achieve a common goal (Hughes 1983). Large technological systems include such technological infrastructures as air transportation, railroad networks, telecommunication systems, and electronic commerce systems. With its complexity and systemic nature, the dynamics of innovation and the nature of industrial coordination are differently characterized from those of mass production goods (Hughes 1983, 1989).

A distinctive feature of the LTS perspective is that it brings the whole complex interconnections and interactions among sub-systems into a unit of analysis. It broadly encompasses not only the technological components such as various technological goods and services but also firms in the related industries and social institutions such as government, universities, industrial policies, and regulations.

In many advanced economies, large technological systems constitute a significant proportion of industrial output and fixed capital formation, and serve as infrastructure upon which goods and services are produced and traded. Therefore, the competitiveness of cutting-edge goods and sophisticatedly tailored services are heavily dependent one way or another on continuous development and advance of large technological systems (Hobday 1998). In other words, it is difficult to understand the innovation mechanisms and future directions of various goods and services without proper consideration of LTS behind them. M obile Internet services are no exception.

How does a large technological system develop and evolve? To deal with this question, Hughes proposed several important analytical concepts, but in this paper we pay attention to his concept of reverse salients (Hughes 1983, 1989). A reverse salient refers to a component in the system that has fallen behind or is out of phase with the others. It is comparable to components in needs of attention such as drag, 
limits to potential, emergent friction, and system inefficiency. In a mature, complex technological system the need for new organizational arrangement may often be a reverse salient (Hughes 1989). Thus, the way in which a reserve salient, or a lagging component and part, of the system is coped with and comforted to the others could be a decisive factor for the future direction and speed of LTS development.

In a sense, a reverse salient shares some common conceptual grounds with "focusing device" presented by Rosenberg (1976), which refers to developmental imbalances in an interdependent technological system and production system. In this approach Rosenberg focused on a "technological" imbalance for the explanation of innovation process, especially delving into timing and direction of new technological innovations. Application of reverse salients, however, is not necessarily limited to technological components of the systems. It could be applied to organizational and institutional components of the systems. Given the unprecedentedly high speed of changes in information and communication technologies, continuous restructuring and realigning social institutions in accordance with technological advances will be critical in order to realize their potentials and reap newly presented benefits. A reverse salient caused by social institutions would therefore merit our keen attention in this field.

Drawing on this perspective, this paper will analyze the developmental process of mobile music businesses in Japan and Korea. To summarize our conclusion briefly in advance, music copyright management institutions have played a role of reverse salient in the development of mobile music businesses, and the way in which music copyright institutions on one hand and rapid changes in mobile technologies on the other hand are aligned would be an important factor to determine the directions and speed of mobile music business development.

\section{Overview of M obile M usic Business in Japan and Korea ${ }^{1}$}

Japan and Korea are ahead of other countries in the diffusion of mobile Internet. At the end of $\mathbf{2 0 0 2}$ mobile communication subscribers reached $63 \%$ of the total population in Japan and 69\% in Korea. Among the subscribers, those owning handsets with a mobile Internet function accounted for $93 \%$ in Japan and $90 \%$ in Korea. The

\footnotetext{
1 For more detailed description of Japanese mobile music businesses and their development process, see Takeishi and Lee (2003).
} 
mobile Internet services, embodied in the $2.5 \mathrm{G}$ mobile communication system, were first launched in February 1999 in Japan and September 1999 in Korea, and have grown rapidly with E-mail and content services. The both countries then moved into the $3 \mathrm{G}$ mobile communication system - in October 2001 in Japan and June 2002 in Korea - with an expectation for further growth and development of mobile Internet businesses.

Among various mobile Internet services, music related services have been the most important businesses in the two countries, commonly having driven the development of mobile Internet businesses as the largest market. So far, the following services have been available in Japan and Korea.

Ringing M elody (Chakumero in Japan : Bellsori in Korea)

Ringing melody is a short melody for mobile handset's ringing tone use. A mobile phone subscriber downloads melody files from content providers to use it as ringing tone. A melody file is coded in variously file formats according to the handset's music processing chip, the download channel, and the carrier's data transmission specifications and capacity. Music processing chip's capacity has rapidly advanced from simple 1-3 chords through 16-40 chords to the current 64 chords, which could replay sound quality cl ose to $C D$ records. There are three different channels for melody selection and downloading: ARS (Automatic Response System), mobile Internet, and PC connected wired Internet. In Korea the ARS download channel had prevailed during the first two years, but mobile and wired Internet channels have recently replaced it. In Japan, although the ARS channel was used initially, due to rapid diffusion of mobile Internet, mel ody downloading through mobile Internet channel has become dominant from its launch.

Ringing Back Song ( $M$ elody Call in Japan: Coloring in Korea)

Ring back song service is a service in which a phone call receiver selects and pays for the music to be played for callers. In stead of old mechanical ringing sound, callers could listen to about 15-seconds of popular music or humorous voices repeatedly while he/ she is waiting for receiver's answering. It was first developed in 2002 in Korea and has become a killer application within just several months. In Japan, NTT 
DoCoMo introduced the similar service in September 2003.

M usic D ownload (Chaku-U ta in Japan: Live Bell in Korea)

This is a service in which a subscriber downloads a portion or full version of music, rather than melody, for ringing tone. This service has become available only with the introduction of mobile music processing chips that achieve high sound quality closer to CDs. A service for downloading a part of music was launched by KDDI in December 2002 in Japan, and a service for downloading full music was introduced in March 2003 in Korea.

These mobile music businesses have grown to build up a large market. The most notable is Japan's ringing melody (“Chaku-Mero") service. As of December 2002, total number of official sites for the three carriers (NTT DoCoMo, KDDI, and J-Phone) reached 244, and Chaku-Mero commanded the largest sales in every carrier's mobile Internet services. Chaku-M ero claimed about $40-60 \%$ of the whole mobile Internet sales for each carrier. It was estimated that in 2002 the three carriers' total revenue from (that is, subscribers' total payment for) paid mobile Internet services was approximately $\mathbf{1 5 0}$ billion yen (approximately 1.5 billion US dollars), and the revenue from Chaku-Mero sites was 80-90 billion yen (800-900 million US dollars), a very rapid growth from zero within three years.

In Korea, ringing melody service is also the most popular mobile content service, accounting for about a half of 23 billion yen (230 million US dollars) total mobile content market. Ringing melody had grown to 8 billion yen (80 million US dollars) market and ringing back song 3 billion yen (30 million US dollars), together creating in total 11 billion yen (110 million US dollars) mobile music market. The mobile music service market has been larger than that of mobile game or those of any other mobile contents in Korea. Furthermore, music download services were launched in both Japan and Korea with the advent of the $3 \mathrm{G}$ mobile communication system. KDDI's ringing song service (Chaku-Uta) has proved to the first killer application in their 3G mobile services (cdma2000).

It should be noted, however, that Korea's mobile music market growth has been somewhat limited when it is compared with that of Japan. There is 8 times market 
size difference between Japan and Korea2. This difference will be addressed later in this paper.

\section{Mobile M usic Business as a Large Technological System}

Consumers simply download their favorite music from content providers by way of mobile Internet network and mindlessly enjoy it. All these electronic transactions, however, are materialized on the background support of complexly interconnected and sophisticatedly aligned large mobile technological system. The large technological system of mobile Internet network is constituted by a variety of sub-systems: mobile communication networks and their carriers; mobile handsets and their manufacturers; mobile communication network hardware and software and their manufacturers; music contents played on handsets and their creators (artists and record companies); mobile music content files and their providers; music copyrights and institutions managing them; and public policies and regulations on mobile communication and government bodies that design and implement them. All of them are a part or component of the large technological system of mobile Internet. Although there will be endless lists if we detail down into the sub-levels, above list may encompass major technological, organizational, and institutional components (artifacts) of the large mobile Internet technological system.

The mobile music services could be materialized only when above mentioned heterogeneous sub-components are sophisticatedly orchestrated and seamlessly structured into a large system. The growth, differentiations, and advancement of mobile music businesses depend on coordinated changes of relevant sub-components or sometimes addition of new sub-components to the system.

Even though Japan and Korea share a certain resemblance in the basic structure of the whole mobile music system, the characteristics of sub-components and

\footnotetext{
2 We should be very careful in this simple market size comparison, because 1) Japanese population is 3 times larger than that of Korea, and 2) GDP per capita of Japan is about 3 times larger than that of Korea. It is therefore natural that the Japanese market is larger than the Korean for any goods and services in general. However, we could argue that the market size of mobile music services in Korea is still smaller than that in Japan even when we take into account the differences in overall economic size and income level. If we look at other cases, the difference between the two countries is narrower than that for mobile music services: for example, three times in mobile handsets sales, three times in information and communication technology industry production, and four times in automobile sales.
} 
relations among them differ. Differences stem from various causes such as the context and path of development of each sub-component, and timing of formation of the system. Since there is no enough space and capacity for us to analyze all the sub-components in this paper, we focus on one important sub-component that could be considered as a determinant to create the national difference of mobile music businesses between Japan and Korea, and as a reverse salient to affect their development processes. It is "institutions to manage and control music copyrights."

\section{Copyright M anagement Institutions as a Reverse Salient}

The basic structure of the ringing melody business in Japan and Korea could be depicted as Figure 1 and Figure 2, respectively. Let's look at Japan's case, first. In Japan, official content provider sites, which are approved by each carrier and listed on the carrier's official menu pages, provide melody download service. Users subscribe to their favorite sites, and download music melodies on monthly fee base or by discrete payment on each download. Each month, on the monthly bill, carriers charge and collect the service fees from subscribers on behalf of the service providers. Carriers gain their own business revenue by charging (1) data communication time (the packet communication fee, for instance, costs around 6-7 yen (6-7 US cents) for a ringing melody download) to subscribers for their site access, and (2) a fixed rate of handling fee to content providers (Docomo and KDDI charge $9 \%$ and J-phone $12 \%$ as the handling fee of the collected revenue for the provider). And, the service providers pay the copyright fees to the Japanese Society for Rights of Authors, Composers, and Publishers (JASRAC). For melodies shorter than 45 seconds 5 yen ( 5 US cents) per melody is charged, and 7.7 yen (7.7 US cents) for melodies longer than 45 seconds.

It is important to point out that most of the music copyrights for ringing melody are trusted to and managed by JASRAC in Japan³. As JASRAC has taken charge of copyright procedures for most of ringing tone melodies, ringing melody service providers could use most of popular musical tunes rather freely as far as they

\footnotetext{
${ }^{3}$ After the enactment of the Laws on Management Business of Copyright and Neighboring Rights in October 2001, a number of commercial organizations have been permitted to enter the business of musical copyright administration. Before that, JA SRAC had been a sole institution for musical copyright administration in Japan. Despite this change, JASRAC has still maintained its position as a dominant institution for music copyright management.
} 
pay the fees to JASRAC. A historical background of such smooth copyright coordination for the melody service could be traced back to institutional arrangements made for the Karaoke business and J-Phone's Sky Melody service, which provided ringing melody service based on ARS system on SMS network. For the ringing melody service, the copyright negotiations with JASRAC were conducted by the Association of Musical Electronics Industry (AMEI) with the leadership of Yamaha, Faith, and major service providers. They agreed on the current copyright rule in late 2000 , about one year after the first ringing melody download service was introduced.

In the beginning, as ringing melody gained wide popularity, a large number of general sites (or unofficial sites not approved by the career) for ringing melody sprung into existence, offering a wide variety of free melody download services. To counter this undesirable trend, JASRAC vigorously monitored and charged copyright violations, and eventually cooled down the movement. JASRAC thus made an important contribution to the ringing melody business by preventing the spread of improper free services, in addition to the provision of smooth copyright coordination. This evolution pattern contrasts with the U.S. situation in which an earlier wide spread of free music download services like Napster on the fixed Internet has disturbed the creation of paid online music download services, having established the first image of "free music on the web."

When we look at other countries, we find that the situations are also not as efficient and effective as the Japanese case. As shown in Table 1, for example, in some countries copyrights are managed in a more complicated manner with different rules, and/ or there is no institution that could manage necessary copyrights all together for one-stop shopping, raising the cost of copyright coordination or allowing the spread of illegal, or free, download sites. Indeed, Japanese service providers often complain about the absence of desirable copyright procedures as a major obstacle for their business overseas.

Korea is one of such countries. As you see in Figures 1 and 2, Korea and Japan look similar in the basic structure of ringing melody business. However, there are some seemingly subtle but critical differences, which do matter very much to the development of mobile music businesses. In Korea general recognition for copyright protection in general has been comparably weak not only among users but also among 
music content service providers and copyright claimers. Officially, it has been principle that all copyright fees are to be collected by Korea Music Copyright Association (KOMCA) and to be redistributed to the copyright owners. As a rule, any mobile music content providers could initiate service by paying required copyright fees. While no specific copyright rule for ringing melody is formulated, content providers are usually supposed to pay $6.5-8 \%$ of download service revenue as copyright fee. However, the reality and practices are that no accurate data recorded regarding every melody service transaction is available neither from content providers nor from mobile carriers, prohibiting exact copyright calculations for each music download. Therefore, the practical rule is that music content providers pay $6.5-8 \%$ of business revenue as copyright fee on monthly basis, causing problems of limited transparency in copyright control and transactions. To make things worse, there exist some copyrights that are not trusted to KOMCA. This sometimes provokes legal conflicts between content providers and copyright holders who would demand additional copyright charges.

Due to weak copyright recognition regarding musical products in general and limited capacity and ambiguous rules of copyright management institutions, many companies have provided music service without paying due attention to copyright issues. Furthermore, all these ambiguous principles and improper institutional operations have given birth to 'illegitimate' or 'inadequate' free services, which could blow substantial and unjust competitive damages to legitimate service providers and would not properly compensate creative efforts of artists, thus sealing the further market growth potentials and providing less incentive to music creation activities. In effect, music copyright institutions in Korea have been unable to justly protect and properly manage musical copyrights, and have thus failed to contribute to further market growth.

In Japan, owing to efficient and effective copyright operation mechanism, any mobile music content providers could legitimately build up music services just by paying due fees to JASRAC based on accurate records of download transactions. Without competing against illegitimate free sites, the legal, official service providers could reap proper returns for its initial investments. It also works in such a way that easy market entry strongly propels market competition among multiple content providers, pressing each provider to differentiate their service and create new values 
for survival. In this manner, smooth copyright coordination has substantially contributed to the success of Japan's ringing mel ody business.

However, the story does not stop here. Though Japanese copyright institutions have worked effectively for ringing melody, a different scenario could be sketched for music download service market. Ringing melody services only use melody. Only composers are paid for their 'copyright in musical compositions.' On the other hand, ringing song and ringing back song use original music, usually with songs and instrumental performance, for which a full set of copyright fees should be paid to multiple parties such as composers, lyricists, singers, musicians, recording companies, and artist management offices that hold related copyrights, which is equivalent to 'copyright in sound recordings' in the copyright law of the U.S. Copyright issues for mobile services to download musical song are therefore much more complicated than for those to download simple musical melody.

NTT DoCoMo, which has successfully developed i-mode service and nurtured ringing melody market, has provided full music distribution service, the M-stage, in its PHS mobile platform without using Internet channel. However, the demand for this service has been rather limited partly because of complex copyright issues. Due to concerns for illegal usages and demand for strong copyright protection, the service is rather expensive and the number of music available is limited.

On the other hand, KDDI's ringing song ("Chaku-Uta") service, introduced on their 3G platform, uses a part of music and has managed to clear copyright protection concerns by limiting the scope of music file usages only to the handset. So far, the service has been smoothly launched and proved to be a new killer application. One notable fact is that record companies, which could not gain any benefits from lucrative ringing melody business, are now reaping their investment for creating and promoting popular music. A joint venture of major Japanese record companies, “Label Mobile," has launched ringing song download business with their legal copyrights over original music, which cannot be fully covered by JASRAC. So, content providers for ringing melody cannot enter the ringing song business, and record companies thus provide the ringing song service of the music under their control exclusively. Yet, there are many popular songs that are not offered for ringing song service, because their 
copyrights are not owned by record companies but by individual artists and other artist management firms, some of which are not interested in mobile music business. So, whereas in the ringing melody service multiple service providers covered most of popular music, in the ringing song service each music is provided by a single service provider and the scope of music available for the service is still somewhat limited.

Furthermore, if we move to more advanced mobile music services, where full music download service and data exchanges across mobile handsets, PC and other audio devices are very feasible, copyright protection and proper coordination would become much more complex and problematic. The seriousness of this problem could be easily grasped when we just look at the bitter experiences with Napster in the U.S.

Given this situation, it is interesting to observe that currently in Korea nation-wide coordination and registration efforts have been made to establish new copyright institutions, which administer all digitalized music content services, be it fixed or mobile. The new movement is fully joined by government policy makers, associations of record companies and artists, and wired and wireless online content providers. It has been generally agreed by all the interest groups that "a new copyright institution and management body is in urgent needs and the access to copyright should not be exclusively monopolized by some parties."

Our observation has indicated that music copyright institutions could be regarded as a reverse salient in the large technological system of mobile music businesses. Technologies to process, transmit and replay music have ceaselessly advanced with development of information and communication technologies. Such technological progress has created and will continue to create enormous potentials for cheaper, faster, and better mobile music services. However, in order to materialize new technological potentials into real business chances and enable new service providers to be smoothly wheeled into the evolving large technological system, the corresponding copyright institutions should be timely rearranged in accordance with other sub-components and their technological changes in the large system.

Such alignments are not easy as they are described. Copyright problems could provide one explanation for why Korean mobile music market is smaller than Japan. Also, Japan's institutional success in ringing melody will not guarantee another 
success in full music download services without proper revision of its copyright institutions (see Table 2 for related institutions in Japan for advanced services). On the other hand, in Korea, although it is still too early to condude, it could be speculated that early copyright problems could serve as a springboard for the creation of more advanced copyright management institutions, fully supporting the future development of new mobile music businesses. ${ }^{4}$

Different from technological problems residing in specific hardware and software or organizational problems arising within individual firms, music copyright problems necessitate a complex social re-engineering across various entities with diverging, usually conflicting interests. Because of the difficulty of such social reengineering, it would easily become a reverse salient in the whole system and a critical determinant for directions and timing of future evolution of mobile music businesses.

\section{Conclusion}

Mobile music businesses have been the largest contributor to the successful launch and subsequent growth of mobile Internet and content market in Japan and Korea. However, the comparative analysis of two countries' mobile Internet systems highlighted some differences in copyright management institutions. We argued that Japanese institution for ringing melody has nurtured the significant growth of mobile music market, while Korea has lacked such institution. However, for the next stage of mobile music content services Japanese institutions are not yet fully prepared, while Korea seems to be making efforts to create new institutions. The institutionalization process for efficient and effective management of music copyrights would be a key factor determining the future development of mobile music business in both Japan and Korea.

\footnotetext{
${ }^{4}$ Signs promoting such speculation are slowly appearing. Since the mid-2003, numerous private and public organizations mediating copyright in sound recordings have been established and the practical as well as official new copyright rules are being institutionalized. With these new copyright institutions and with no copyright-erected entry barrier, most of incumbent major ringing melody content providers as well as new entrants have already moved to new market of ringing song and full music download services. Multimedia content services feasible on the 3G platform, such as full mobile music download, and music video and music streaming service, have been creating new markets, and generating, for instance, 20 billion yen (200 million US dollars) sales revenue in 2003 only for SKT. The markets are expected to further expand by the introduction of MP3 playing mobile phones in the mid-2004.
} 
By adopting the large technological system perspective, we have observed that copyright institutions could be seen as a reverse salient against rapid advances of mobile music businesses to provide better contents faster and more cheaply to make full of technological progress. Realignment of social institutions, which usually embroil a variety of conflicting entities, often causes more complex problems than that of particular technologies, products, or services, consuming considerable social efforts and energies, and demanding creative institutional solutions and political coordination.

It is therefore important to pay more attention to social and political factors in understanding and managing mobile Internet market and businesses. This argument echoes with Tushman and Rosenkopf (1992), who emphasized the importance of social and political elements in technological changes. They pointed out that such elements are particularly influential for open systems during eras of ferment. Indeed, mobile music business is a part of ever-changing open network system, where eras of ferment arrive cyclically at frequent intervals. As shown in this case of mobile music business development, one distinctive nature and impact of explosively progressing information and communication technologies is that technological potentials frequently necessitate corresponding realignments of social institutions.

It suggests that public policy and regulations are important for developing mobile Internet commerce and that laissez fair economic policy approach may not always be the best solution. It also suggests that managers are advised to pay more attention to social institutions and public policies. Competitive strategy tends to focus on economic factors. For example, Porter (1980) asserted, "although the relevant environment is very broad, encompassing social as well as economic forces, the key aspect of the firm's environment is the industry or industries in which it competes." However, to be successful in the field of mobile Internet, companies should learn more how to bring changes in social and political realms effectively and timely to their advantage.

For those who study mobile Internet market and businesses, a critical question in the mobile Internet research would be how we could laboriously adjust social institutions against the disruptive technological changes and what impacts it would have on the paths and directions of technological innovations. 


\section{References}

Hobday, Mike (1998). "Product Complexity, Innovation and Industrial Organization," Research Policy, vol. 29 (6), pp.698-710.

Hughes, Thomas P. (1983). N etworks of P ow er: Electrification in W estern Society, 1890-1930. Baltimore: John Hopkins University Press.

Hughes, Thomas P. (1989). "The Evolution of Large Technological Systems," in Wiebe E. Bijker, Thomas P. Hughes, and Trevor Pinch (eds.), The Social Construction of Technological Systems. Cambridge, MA: MIT Press, pp. 51-82.

Porter, Michael E. (1980). Competitive Strategy: Techniques for Analyzing Industries and Competitors. New York: Free Press.

Rosenberg, Nathan (1976). Perspectives on Technology. New York: Cambridge University Press.

Takeishi, Akira and Kyoung-Joo, Lee (2003). "Mobile Innovation and the Music Business in Japan: The Case of Ringing Tone Melody ("Chaku-Mero") (Research Note)," Working Paper \#03-08, Hitotsubashi University Institute of Innovation Research.

Tushman, Michael L. and Lori Rosenkopf (1992). “Organizational Determinants of Technological Change: Toward a Sociology of Technological Evolution." in L. L. Cummings and B. M. Staw (eds.), Research in Organizational Behavior, 14. Greenwich, Conn., JAI Press, pp. 311-347. 
Figure 1. Basic Structure of Ringing Melody Business in Japan

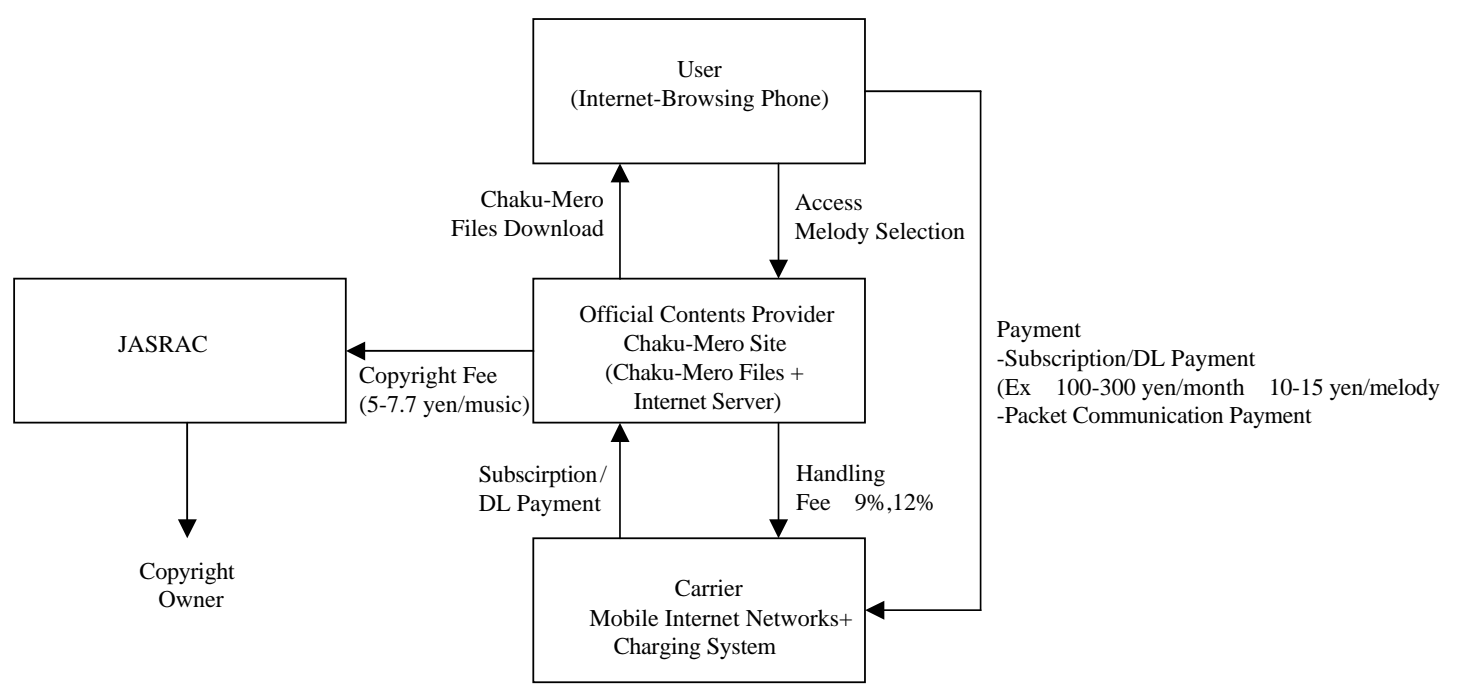




\section{Figure 2. Basic Structure of Ringing Melody Business in Korea}

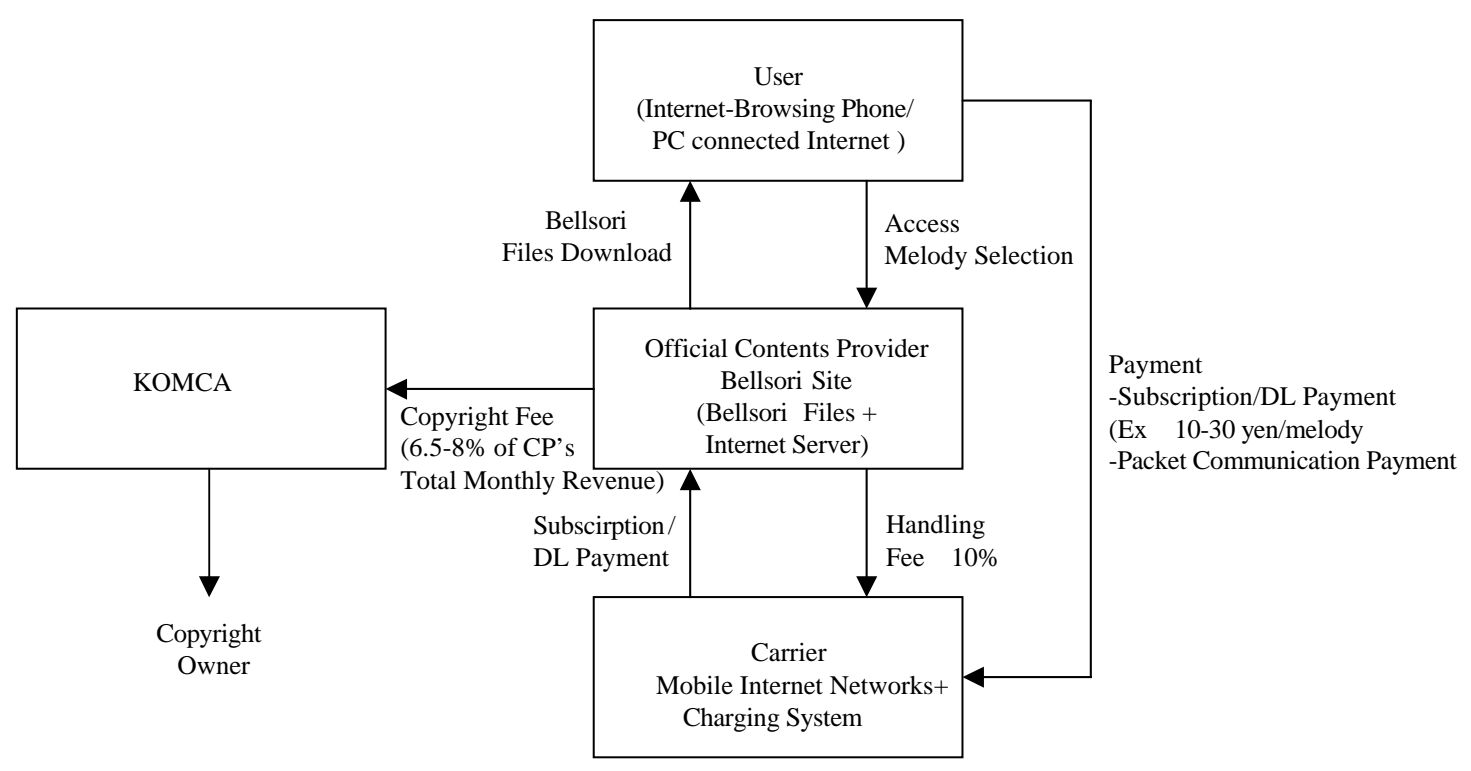


Table 1. Institutions for Chaku-Mero Related Copyrights in Some Countries

\begin{tabular}{lll}
\hline Country & $\begin{array}{l}\text { Institutions for } \\
\text { Copyrights } \\
\text { Coordination }\end{array}$ & Characteristics, Problems, etc \\
\hline Japan & JASRAC & $\begin{array}{l}\text { As JASRAC collectively controls almost all the copyrights, it could } \\
\text { efficiently coordinate copyrights for Chaku-Mero providers. }\end{array}$ \\
U.S.A & ASCAP,BMI, etc & $\begin{array}{l}\text { Because of multiple numbers of copy right institutions, copy right } \\
\text { coordination process is complex. }\end{array}$ \\
Germany & GEMA, etc & $\begin{array}{l}\text { The copyright rule requires Chaku-Mero service providers to pay } 0.2 \\
\text { Euro for the composer as they transform the original music into } \\
\text { Chaku-Mero, the distribution cost is high. }\end{array}$ \\
Singapore & COMPASS & $\begin{array}{l}\text { Because there is no effective collective copyright institutions, } \\
\text { coordination procedurals are difficult. }\end{array}$ \\
\hline
\end{tabular}

Source: Nihon Keizi Shinbun, 2003/02/08 Table 2. Copyrights Owners and Related Institutions
for Mobile Music Services in Japan

\begin{tabular}{lll}
\hline Mobile Music Business & Copyright Owners & Related Institutions \\
\hline Melody Downloading & $\begin{array}{l}\text { Compsers, MIDI data } \\
\text { creators }\end{array}$ & $\begin{array}{l}\text { JASRAC (Japanese Society for Rights of Authors, } \\
\text { Composers, and Publishers), AMEI (Association of } \\
\text { Muiscal Electronics Industry) }\end{array}$ \\
Music Downloading & $\begin{array}{l}\text { Compsers, Lyricists, } \\
\text { Singers, Performers, } \\
\text { Master tape producers }\end{array}$ & $\begin{array}{l}\text { JASRAC, RIAJ (Recording Industry Association of Japan), } \\
\text { CPRA (Center for Performers' Rights Administration), } \\
\text { JAMederation of Music Producers Japan) }\end{array}$ \\
$\begin{array}{l}\text { (Ferprises), FMP } \\
\text { Advertising Music }\end{array}$ & $\begin{array}{l}\text { Compsers, Lyricists, } \\
\text { Downloading }\end{array}$ & $\begin{array}{l}\text { JASRAC, RIAJ, CPRA, JAME, FMP, JAAA (Japan } \\
\text { Advertising Agencies Association) }\end{array}$ \\
\hline
\end{tabular}

